\title{
Preparo de alta para o cuidado domiciliar de recém-nascidos de baixo risco
}

\author{
Preparing for discharge of low-risk newborns to home care \\ Preparación de alta para el cuidado domiciliar de neonatos de bajo riesgo
}

\begin{abstract}
Fernanda Carla Pereira Duarte'; Fernanda Garcia Bezerra Góes"; Andrea Lyra Arnozo da Rochall'; Joana de Andrade Nobre Ferraz ${ }^{\prime V}$; Juliana Rezende Montenegro Medeiros de Moraes ${ }^{v}$; Liliane Faria da Silva ${ }^{v /}$
\end{abstract}

\begin{abstract}
RESUMO
Objetivo: analisar o preparo de alta de famílias no alojamento conjunto quanto aos cuidados domiciliares dos recém-nascidos. Método: pesquisa qualitativa, desenvolvida através de Dinâmicas de Criatividade e Sensibilidade Corpo Saber, do Método Criativo Sensível, junto a 17 participantes, entre puérperas e familiares, em um hospital municipal da baixada litorânea do Rio de Janeiro, entre 2017 e 2018, cujos dados foram submetidos à análise temática. Aprovado por Comitê de Ética em Pesquisa. Resultados: o preparo de alta abarca orientações principalmente sobre aleitamento materno e manejo do coto umbilical, mas incluem conteúdos sobre banho, posições confortáveis e vacinas. Enfermeiras assumem o papel social de educadoras, através de uma prática educativa pontual baseada na transmissão de informações e na demonstração do cuidado do recém-nascido. Conclusão: existem lacunas no preparo de alta quanto às orientações essenciais para o cuidado domiciliar do recém-nascido com segurança e qualidade, ademais, é preciso buscar abordagens pedagógicas dialógicas que partam da realidade das famílias. Descritores: Recém-nascido; alta do paciente; educação em saúde; enfermagem.
\end{abstract}

\section{ABSTRACT}

Objective: to examine preparations for discharge of families in the rooming-in facility as regards home care for newborns. Method: this qualitative study research, conducted through Body Knowledge Creativity and Sensitivity Dynamics, as part of the Sensitive Creative Method, in 2017 and 2018, at a municipal hospital in the Rio de Janeiro coastal lowlands, with 17 participants, including puerperas and family members The resulting data were treated by thematic analysis. The study was approved by the research ethics committee. Results: preparation for discharge includes guidance mainly on breastfeeding and management of the umbilical stump, but also bathing, comfortable positions and vaccines. Nurses perform the social role of educators by circumstantial educational actions basically to convey information and demonstrate care for the newborn. Conclusion: in the preparation for discharge, there were gaps in essential guidance on safe, quality home care for newborns, and dialogical pedagogical approaches, taking the families' realities as their point of departure, should be encountered.

Descriptors: Newborn; patient discharge; health education; nursing.

\section{RESUMEN}

Objetivo: analizar la preparación de alta de familias en el alojamiento conjunto respecto a los cuidados domiciliarios de los neonatos. Método: investigación cualitativa, desarrollada a través de Dinámicas de Creatividad y Sensibilidad Cuerpo Saber, del Método Creativo Sensible, junto a 17 participantes, entre puérperas y familiares, en un hospital municipal de la costa de Río de Janeiro, entre 2017 y 2018, cuyos datos fueron sometidos al análisis temático. Aprobado por el Comité de Ética en Investigación. Resultados: la preparación de alta abarca orientaciones principalmente sobre lactancia materna y manejo del cordón umbilical, pero incluyen contenidos sobre baño, posiciones confortables y vacunas. Enfermeras asumen el papel social de educadoras, a través de una práctica educativa puntual basada en la transmisión de informaciones y en la demostración del cuidado del neonato. Conclusión: existen deficiencias en la preparación de alta en cuanto a las orientaciones esenciales para el cuidado domiciliar del neonato con seguridad y calidad; además, es necesario buscar enfoques pedagógicos dialógicos que partan de la realidad de las familias.

Descriptores: Recién nacido; alta del paciente; educación en salud; enfermería.

\section{INTRODUÇÃO}

Os familiares de recém-nascidos precisam aprender a cuidar de seus bebês preparando-se para o cuidado domiciliar. Nesse sentido, o processo de alta no alojamento conjunto, que inclui o preparo das famílias, torna-se relevante, devendo começar desde a admissão do binômio, e conter orientações relativas aos cuidados sobre higiene, alimentação, manuseio, comportamento, interação, posição para dormir, acompanhamento no sistema de saúde, dentre outros ${ }^{1}$.

'Enfermeira. Universidade Federal Fluminense. Brasil. E-mail: fc.duarte12@gmail.com

"Enfermeira. Doutora em Enfermagem. Professora Adjunta. Universidade Federal Fluminense. Brasil. E-mail: ferbezerra@gmail.com

'"Enfermeira. Universidade Federal Fluminense. Brasil. E-mail: andyjovem@gmail.com

IVEnfermeira. Universidade Federal Fluminense. Brasil. E-mail: joanaferraz.rc@hotmail.com

vEnfermeira. Doutora em Enfermagem. Professora Adjunta. Universidade Federal do Rio de Janeiro. Brasil. E-mail: jumoraes333@gmail.com

VIEnfermeira. Doutora em Enfermagem. Professora Adjunta. Universidade Federal Fluminense. Brasil. E-mail: lili.05@hotmail.com

VIIFomento: Conselho Nacional de Desenvolvimento Científico e Tecnológico. 
Logo, a transição de recém-nascidos de baixo risco do hospital para casa demanda ações educativas, por parte dos profissionais de saúde, incluindo o enfermeiro, adequadas às reais necessidades das famílias. Para tal, é preciso convidar os familiares a saírem da passividade diante das práticas da equipe de saúde, por meio de ações educativas que partam da realidade por eles vivida, em uma relação verdadeiramente dialógica².

Nessa lógica, a educação em saúde é compreendida como um conjugado de práticas pedagógicas dialógicas, participativas e emancipatórias, com vistas a facilitar ações voluntárias à saúde, que não se reduzem a mera transmissão de conteúdos, sendo, portanto, considerada uma ferramenta essencial de promoção da saúde ${ }^{3}$. Assim, é fundamental que toda ação educativa em saúde seja baseada no diálogo, e não se reduza a um ato de depositar ideias de um sujeito no outro pela imposição de suas verdades, visto que a conquista, implícita no diálogo, é a do mundo pelos sujeitos dialógicos, não a de um pelo outro ${ }^{4,5}$

Na busca de boas práticas relacionadas à alta de recém-nascidos, verificou-se que os estudos científicos nacionais e internacionais se concentram basicamente na alta da unidade de terapia intensiva neonatal e/ou dos recém-nascidos prematuros e/ou de baixo peso, sendo raros os estudos que descrevem encontros educativos em outros cenários de práticas, como, por exemplo, dos profissionais de saúde e das famílias de bebês de baixo risco. Portanto, neste estudo ${ }^{V I I}$ objetivou-se analisar o preparo de alta de famílias, no alojamento conjunto, quanto aos cuidados domiciliares dos recém-nascidos.

\section{REFERENCIAL TEÓRICO}

Esta pesquisa se apoia nas concepções teóricas da educação problematizadora defendida por Paulo Freire, que se concretiza como prática de liberdade por romper com a verticalidade da prática bancária e propor, por meio do diálogo, uma relação transversal e dialógica entre os sujeitos. A educação problematizadora tem o caráter essencialmente reflexivo e implica constante interrogação crítica da realidade ${ }^{4,5}$.

A partir do diálogo e da troca de saberes técnico-científicos e populares, enfermeiros e famílias podem construir de forma compartilhada um saber sobre os cuidados domiciliares do recém-nascido com qualidade e segurança, que possa favorecer o crescimento e o desenvolvimento infantil saudável e harmonioso.

Logo, é necessário que se desenvolva um processo de alta dialógico, emancipatório e participativo, que tem por finalidades desenvolver as habilidades dos familiares no cuidado, diminuir o nível de stress da família, evitar reinternações e identificar recursos comunitários disponíveis para seguimento após a alta hospitalar ${ }^{6}$. Assim, no processo de cuidar/ensinar é necessário o conhecimento da realidade da família, vislumbrando o uso de estratégias que venham, de fato, atender às suas reais necessidades, sempre respeitando suas peculiaridades culturais ${ }^{7}$.

\section{METODOLOGIA}

Pesquisa qualitativa ${ }^{8}$, realizada no alojamento conjunto de um hospital municipal da baixada litorânea do Rio de Janeiro, entre 2017 e 2018.

Optou-se pelo Método Criativo-Sensível (MCS) que permite ao pesquisador observar o objeto por uma perspectiva histórico-social, uma vez que estimula a socialização de experiências e vivências adquiridas ao longo da vida, através das Dinâmicas de Criatividade e Sensibilidade (DCS), que conjugam produções artísticas com a discussão grupal e a observação participante, a partir de uma Questão Geradora de Debate (QGD) ${ }^{9}$

Sete DCS Corpo Saber foram desenvolvida com 17 participantes, entre puérperas e familiares cuidadores, com idade superior a 18 anos, cujos recém-nascidos estavam em boas condições de saúde e internados no hospital, cenário da pesquisa.

As DCS Corpo Saber objetivaram despertar os participantes para representar, no corpo desenhado de um bebê, os cuidados que eles estavam aprendendo, durante a permanência no hospital, para cuidar de seus recém-nascidos em casa, considerando que o preparo de alta é um componente essencial nesse processo.

O número de participantes foi delimitado no decorrer do trabalho de campo, quando a organização dos depoimentos, oriundos das DCS, possibilitou a identificação da saturação dos dados, ou seja, a verificação da singularidade dos achados nos discursos, de acordo com os temas, e da consistência dos enunciados ${ }^{10}$.

Todos participantes foram identificados com a letra $\mathrm{P}$, para garantir o anonimato, seguida do número arábico correspondente à ordem de participação nas dinâmicas, por exemplo, P1, P2, P3 e, assim, sucessivamente.

Os dados produzidos, a partir da transcrição na íntegra das dinâmicas, foram submetidos à análise de conteúdo sob a perspectiva temática, em suas três etapas (pré-análise, exploração do material e tratamento dos dados e interpretações) $)^{8,10}$. 
Da análise dos dados, emergiram duas categorias temáticas: orientações no preparo de alta para o cuidado domiciliar com o recém-nascido e o encontro educativo entre enfermeiras e famílias no preparo de alta.

O projeto do estudo foi aprovado pelo Comitê de Ética em Pesquisa (CAAE: 69912317.8.0000.5243; Parecer no 2180258) e todos os participantes assinaram o Termo de Consentimento Livre Esclarecido e o Termo de Autorização de Gravação de Áudio e de Registro Fotográfico para Produção Artística.

\section{RESULTADOS E DISCUSSÃO}

Orientações no preparo de alta para o cuidado domiciliar com o recém-nascido

As puérperas e os familiares mencionaram que durante o período de internação no alojamento conjunto foram realizadas, por profissionais de saúde, orientações sobre os cuidados com o recém-nascido. As temáticas das orientações foram focadas, principalmente, no aleitamento materno e no manejo do coto umbilical. Tópicos menos recorrentes nas falas se relacionaram à higiene corporal, sono, posições confortáveis e vacinação.

\section{Aprendi com a enfermeira como é que bota para mamar. (P10)}

Aprendi a dar o peito corretamente [...]. (P6)

Aprendi a amamentar [...]. (P17)

O aleitamento materno foi o tema mais abordado nas práticas educativas realizadas pelos profissionais de saúde, especialmente a enfermeira. Esse achado corrobora a Portaria no 2068, de 21 de outubro de 2016 do Ministério da Saúde que determina, dentre as finalidades do alojamento conjunto, os seus intuitos, a promoção dessa prática sob livre demanda, por meio do apoio às puérperas em possíveis dificuldades e respeitando as necessidades e características individuais do binômio mãe-filho ${ }^{11}$.

Entre as orientações vinculadas ao aleitamento materno, a pega correta foi recorrente, sendo reconhecidos, pelos participantes, os seus benefícios para a prevenção de fissuras mamilares, além de uma alternativa para o bebê amamentar corretamente.

[Aprendi] para a criança encaixar a boca completa tanto no bico, quanto na aréola maior. (P10)

[O bebê] fazer um bocão, botar o dedo, depois vai tirando o dedo devagarzinho para o bebê aconchegar a boca no peito, para ele poder mamar direito. (P12)

Aprendi como amamentar meu filho, que a minha pega estava errada, estava machucando meu seio. (P13)

[A enfermeira] me ensinou a pegar o bico do seio e ir modelando-o para botar na boca do neném [...] e também para pegar direito o peito e não causar nenhum ferimento. (P14)

Além dos cuidados com a pega correta, a posição confortável para amamentar também foi relatada pelos participantes.

[A enfermeira] disse que tem que colocar barriga com barriga e a cabecinha de modo certo no braço [...]. (P6)

[A enfermeira] ensinou como colocar o bebê pra amamentar, chegar bem, aconchegar bem o bebê na barriga. (P12)

Aprendi [...] como amamentar, confortavelmente. (P14)

Apesar da menor recorrência e pouco aprofundamento, orientações sobre a oferta de leite no copinho, o colostro e o tempo entre as mamadas também foram relatadas.

Deixar o neném mamar. Se ele estiver dormindo deixar até 3 horas mais ou menos [...]. (P2)

Ensinou [se referindo à ordenha manual das mamas], tirou no copinho para ele amamentar [...] porque o leite não estava saindo. [...] E que é importante o primeiro leite colostro [...]. (P17)

Nota-se, portanto, que a principal preocupação no alojamento conjunto por parte dos profissionais é com a amamentação. Tal dado coaduna com estudo realizado em um hospital público em Fortaleza, com 20 puérperas ${ }^{12}$. A equipe de saúde deve estar preparada para as orientações acerca da amamentação, proporcionando um aleitamento eficaz para a puérpera e recém-nascido, sem causar danos provenientes de técnicas mal sucedidas ${ }^{13}$. Entretanto, para garantia da eficácia da prática educativa, é preciso dar voz aos familiares para que possam expressar suas expectativas e contextos de vida, de modo a torná-la menos prescritiva e mais dialógica.

Ressalta-se que de acordo com o Ministério da Saúde, é de suma importância que a família seja orientada pelos profissionais de saúde sobre aleitamento materno, não uso de mamadeiras e chupetas, mas são essências também orientações sobre comportamento normal do recém-nascido, interação com bebê, posição para a criança dormir e acompanhamento da criança no serviço de saúde ${ }^{1}$. Essas últimas orientações não foram resgatadas nas memórias das puérperas e familiares, no momento das dinâmicas, o que pressupõe uma lacuna no preparo de alta. 
A higienização do coto umbilical foi o segundo cuidado mais abordado pelos profissionais de saúde em suas práticas educativas, incluindo a aplicação do álcool a $70 \%$ no local e o seu arejamento, segundo mencionam certos participantes.

Aprendi em relação ao umbigo, que antes o povo colocava um monte de besteira nos umbigos e não tem necessidade disso, agora. Colocar um álcool, secar bem sequinho. (P1)

Eu estava limpando de uma forma, eu botava o álcool 70 com a gaze, mas tampava com a fralda. Então aprendi que não deve abafar, porque, como a pediatra falou, que ele é um tipo de ferida, então quanto mais ficar fechado, mais demora pra cicatrizar. (P4)

Também aprendi a higienizar o umbigo de forma correta. (P5)

Vale destacar que o manejo adequado do coto umbilical previne infecções neonatais, o que torna essencial a sua abordagem desde o pré-natal ao pós-alta do alojamento conjunto. As substâncias mais recomendadas para a antissepsia local é o álcool a $70 \%$ e a clorexidina alcoólica a $0,5 \%$, porém, o primeiro é o mais utilizado no Brasil ${ }^{14}$, inclusive no cenário da pesquisa, conforme os depoimentos.

Ainda em relação aos cuidados com a higiene do recém-nascido, apenas dois participantes relataram que aprenderam acerca do banho e a fala de um deles reforça a necessidade desse tipo de orientação no alojamento conjunto.

Aprendi a dar banho no bebê, hoje. Porque normalmente a gente acha que sabe, mas não sabe. (P8)

E aprendi a dar banho. (P17)

Destaca-se que esse momento requer extremo cuidado, devido aos riscos de hipotermia do recém-nascido, ressecamento e irritações na pele. A termorregulação deve ser considerada, pois o recém-nascido ao perder calor pode sofrer hipóxia, acidose metabólica e hipoglicemia. Ademais, os banhos diários e uso de sabonetes podem prejudicar a maturação do manto ácido, elevando o pH da pele, diminuindo o fator de proteção, o que aumenta os riscos de infecção ${ }^{15}$. Essa gama de cuidados impõe a necessidade de orientações minuciosas sobre essa prática, contudo, de acordo com os depoentes, inferem que as orientações acerca do banho foram escassas e pouco aprofundadas pelos profissionais de saúde.

As orientações sobre posições confortáveis para manter o bebê e manejo das cólicas também foram raras.

[A enfermeira] ensinou a segurar também, para não chacoalhar muito. (P8)

A enfermeira me ensinou como que acorda a criança [...]. Posições de como embalar bem [...] e a posição boa para poder aliviar a cólica do neném. (P10)

Aprendi a embrulhar o bebê na forma correta, colocá-lo na posição correta, mais confortável para dormir e segurá-lo ele na posição certa pra acalmar a dorzinha da cólica dele. Eu aprendi só isso, porque eu só estive hoje aqui [...]. (P11)

Notou-se uma lacuna quanto à prática educativa relativa à posição mais recomendada para o recém-nascido dormir, que seria a dorsal ${ }^{1}$. Logo, não houve um aprofundamento quanto aos riscos de sufocamento e de morte súbita do recém-nascido. Em outra pesquisa, poucas mulheres receberam a orientação sobre a melhor posição, principalmente após a dieta e orientações sobre risco de sufocamentos ${ }^{12}$, o que vai ao encontro dos achados do presente estudo.

Orientações sobre as vacinas e suas possíveis reações, durante o preparo de alta no alojamento conjunto, também foram menos referidas pelas puérperas e familiares.

E a importância da vacinação, para que serve cada vacina. (P6)

[A enfermeira] explicou sobre as vacinas. As vacinas e os efeitos. (P9)

Esses dados são coerentes com um estudo em que as puérperas não receberam orientações sobre o calendário vacinal dos bebês no alojamento conjunto, revelando a insatisfação quanto ao atendimento dos profissionais que trabalham nesse setor ${ }^{12}$. Além disso, também se verificou que nenhum participante expôs ter sido orientado sobre o encaminhamento para o serviço de saúde para as consultas de puericultura, e realização de testes de triagem neonatal, conforme preconiza a literatura ${ }^{1,6,11,16}$.

\section{O encontro educativo entre enfermeiras e famílias no preparo de alta}

As orientações, no alojamento conjunto, sobre os cuidados com o recém-nascido foram realizadas principalmente por profissionais de saúde, especialmente por enfermeiras, mas, em certas situações, o aprendizado também foi mediado pelos próprios familiares.

Reforça-se que o profissional mais citado, nesse processo educativo, foi a enfermeira, segundo as declarações dos participantes.

Foi a enfermeira, foi ela que me ensinou. [...] Dão dicas boazinhas para as pessoas. (P1) 
Tal dado corrobora a pesquisa que indicou que o enfermeiro com o profissional que mais intervém junto à puérpera, contribuindo para a formação do seu papel materno e do vínculo com o bebê, instrumentalizando-a para o cuidado domiciliar do recém-nascido ${ }^{12}$.

O profissional pediatra também foi resgatado na memória das puérperas e familiares, porém com menor recorrência nos depoimentos.

\section{Foi com a pediatra e a enfermeira. (P6)}

O pediatra que veio aqui, perguntou se [ o bebê ] estava mamando [...]. (P9)

Esse dado reforça a importância das orientações serem realizadas por toda equipe multiprofissional, por meio da responsabilização de todos no preparo dos familiares para a continuidade do cuidado em casa. Estudo aponta que por muitas vezes, há uma sobrecarga do enfermeiro e por conta disso, as orientações não são realizadas em sua totalidade ${ }^{16}$, o que condiz com o presente estudo.

Além dos profissionais de saúde, os familiares e acompanhantes também foram mencionados nas falas, no que tange ao aprendizado de cuidados do recém-nascido.

Do umbigo eu aprendi com a minha mãe. (P3)

A tia [acompanhante] me ensinou [...]. (P15)

Foi minha mãe. (P17)

Pesquisa realizada no Recife, relata que a experiência de gerações anteriores, seja por pais, tios ou avós, representa um apoio e diminui a insegurança no cuidado ao recém-nascido, além disso, um ambiente familiar saudável e harmonioso possibilita maior compreensão das dificuldades ${ }^{16}$.

Cumpre destacar que o encontro educativo entre enfermeiras e famílias, no preparo de alta, foi baseado essencialmente nas orientações verbalizadas pelas profissionais.

[A enfermeira] falou 'não precisa botar besteira, nada, nada dessas coisas, só isso'. Aí eu aprendi [se referindo ao cuidado do coto umbilical com álcool 70\%]. (P1)

[A enfermeira] disse que tem que colocar barriga com barriga, a cabecinha de modo certo no braço [se referindo à posição para amamentação]. (P6)

Hoje, [a enfermeira] me explicou que eu estava fazendo ao contrário, botando a fraldinha ali para dentro, ela foi e falou que não pode. É para colocar por baixo e o umbiguinho para fora [se referindo ao cuidado do coto umbilical]. (P8)

A moça [a enfermeira], que veio aqui dar a injeção, falou é a $B C G$, essa aqui é a BCG, ela vai ter isso, isso e isso, ela vai inflamar, assim e assim.'(P9)

Além disso, os participantes relataram que esse processo educativo também ocorreu por meio da fala associada à demonstração do cuidado, novamente com a presença recorrente da enfermeira nessa prática educativa.

[A enfermeira] chegou na sala e cuidou [do bebê] e mostrou pra gente. Quem estava ali aprendeu. [...] Ela foi lá, cuidou de um umbiguinho de um neném, mostrou. Falou 'precisa só colocar esse álcool aqui [álcool 70\%]'.

[...] A explicou que tem que secar bem sequinho. (P1)

[A enfermeira] ensinou mostrando e falando, e eu fiquei só observando. (P10)

Sim, me mostraram. [...] Ela [a enfermeira] falou para pegar as gazes, molhar, ir em cima assim e limpar assim. [...] Eu a olhei fazendo. (P15)

Exemplificando esse processo, a enfermeira realizou e explicou o procedimento (o banho) com o recém-nascido para que o familiar observasse.

[A enfermeira] me ensinou, [...] pegou primeiro e lavou a cabecinha do bebê. [...] Depois ela pegou, passou, molhou a gaze na banheira, limpou o rostinho e os olhinhos, depois ela pegou o bebê, colocou dentro da banheira. Ela falou para segurar tipo um ' $C$ ' assim pra dar segurança à criança. Aí deu o banhozinho. (P8)

Logo, o encontro educativo, mediado essencialmente pelas enfermeiras, ocorreu por meio da explicação e/ou demonstração, abarcando a observação e a execução por parte das puérperas e familiares e da supervisão, colaboração e avaliação do desempenho por parte das profissionais. Esse ensinamento, baseado na transmissão de conteúdos e na demonstração de cuidados específicos, tem sido comum no processo educativo entre enfermeiros e pacientes ${ }^{2,7,17}$.

Ainda em relação à estratégia educativa baseada na explicação e na demonstração, a enfermeira utiliza esse momento para auxiliar a puérpera, realizando as orientações na hora em que o participante estava prestando o cuidado. 
[A enfermeira] falou 'segura aqui na pontinha, assim .... que ela [a bebê] mesma vai pegar' [se referindo à pega]. [...] Ela [a enfermeira] fez também para gente ver. (P3)

Só falaram [pediatra e enfermeiras], mas especificando como a gente [as puérperas] estava dando de mamar $e$ as outras [enfermeiras] mexeram nos nenéns, abriu o olharam o umbigo, falou certinho; foi assim. (P6)

[A enfermeira] ensinou tudo direitinho, ensinando na prática. (P11)

[A enfermeira] falou e foi me mostrando, me auxiliando. (P13)

Em síntese, as enfermeiras assumem o papel social de educadora na alta de recém-nascidos do alojamento conjunto, por meio de uma prática tradicional, pontual baseada na transmissão de informações e na demonstração do cuidado.

No modelo tradicional da educação, da pedagogia bancária, baseada na transmissão de conhecimentos, o professor, no caso o profissional de saúde, fornece conteúdos ao aluno, o familiar, como uma verdade absoluta, cabendo a este receber o que lhe foi oferecido sem questionamentos. Contudo, nesse modo de ação é comum a desconsideração dos saberes e crenças dos educandos, construídos nas suas trajetórias de vida, o que torna esse processo educativo descontextualizado ${ }^{4-5}$. Assim, as puérperas e familiares não tiveram oportunidade de expressar suas dúvidas e demandas de aprendizagem, assim como compartilhar seus conhecimentos acerca do cuidado ao recémnascido, o que fragiliza o processo educativo.

Por outro lado, o empoderamento, na perspectiva da educação freiriana, tem como propósito romper com os métodos educativos que estão baseados no poder sobre o outro e enfatizar o modelo que valoriza a discussão de ideias, opiniões e conceitos na busca de solução de problemas ${ }^{4,5,18}$, o que não condiz com o modelo de ensino adotado pelos profissionais no cenário da pesquisa.

Por fim, é preciso ir além da transmissão e a apreensão de conhecimentos, por meio de abordagens pedagógicas problematizadoras, que privilegiam a dialogicidade ${ }^{4,5}$, com a intenção de promover hábitos e atitudes saudáveis. Precisamente é o que se propõe em relação às práticas educativas em saúde sobre os cuidados com o recém-nascido no processo de alta da maternidade.

Ademais, estudos enfatizam a importância de um processo de alta consistente, inclusive com protocolos institucionais, que envolva um trabalho interdisciplinar, para garantir a participação integrada e articulada entre os profissionais e as famílias, vislumbrando, especialmente, a autonomia e a segurança no cuidado ao filho no domicílio ${ }^{19,20}$.

\section{CONCLUSÃO}

Os resultados da pesquisa apontaram que o preparo de alta das famílias de recém-nascidos no alojamento conjunto abarca orientações principalmente sobre aleitamento materno e manejo do coto umbilical e inclui, de forma menos recorrente, conteúdos sobre banho, posições confortáveis e vacinas.

Nesse processo, as enfermeiras assumem o papel social de educadoras, por meio de uma prática educativa tradicional baseada na transmissão de informações e na demonstração do cuidado do recém-nascido, que envolve explicação, demonstração, observação, execução, supervisão, colaboração e avaliação, onde os familiares atuam como receptores dos ensinamentos, sem a contextualização de suas reais dúvidas e necessidades.

Existem lacunas no preparo de alta quanto às orientações essenciais para o cuidado domiciliar do recém-nascido com segurança e qualidade, ademais, é preciso buscar abordagens pedagógicas dialógicas que partam da realidade das famílias.

Espera-se que o estudo contribua com o processo de alta de recém-nascidos por gerar evidências científicas capazes de preencher lacunas do conhecimento, possibilitando uma reflexão crítica, por parte dos profissionais de saúde, incluindo o enfermeiro, sobre esse fenômeno e o repensar das práticas educativas realizadas no alojamento conjunto. Desse modo, vislumbra-se a adoção de estratégias que promovam o empoderamento das famílias, visando uma prática cuidativa segura e com qualidade no domicílio.

Como limitações do estudo, apontam-se a realização em uma única instituição de saúde e apenas com as puérperas e familiares, sem a inclusão dos profissionais. Logo, os resultados refletem parte da realidade, o que impede generalizações, fomentando a necessidade de novos estudos na área, em outros cenários e com outros participantes, para uma compreensão mais abrangente do objeto de estudo.

\section{REFERÊNCIAS}

1. Ministério da Saúde (Br). Atenção à saúde do recém-nascido: guia para os profissionais de saúde. 2a ed. atual. Brasília (DF): Ministério da Saúde; 2014. 
2. Góes FGB, La Cava AM. The conception of education in health of the nurse in the care to the infant hospitalized. Rev. eletrônica enferm. 2009 [cited 2018 Jul 15]; 11(4):932-41. DOI: https://doi.org/10.5216/ree.v11i4.33245

3. Salci MA, Maceno P, Rozza SG, Silva DMGV, Boehs AE, Heidemann ITSB. Health education and its theoretical perspectives: a few reflection. Texto contexto enferm. 2013 [cited 2018 Jul 15]; 22(1):224-30. DOI: http://dx.doi.org/10.1590/S010407072013000100027

4. Freire P. Pedagogia da autonomia: saberes necessários à prática educativa. 43a ed. Rio de Janeiro: Paz e Terra; 2011.

5. Freire P. Pedagogia do oprimido. 50a ed. Rio de Janeiro: Paz e Terra; 2011.

6. Schmidt KT, Terassi M, Marcon SS, Higarashi IH. Practices of nursing staff in the process of preterm baby hospital discharge. Rev. bras. enferm. (Online). 2013 [cited 2018 Jul 15]; 66(6):833-9. DOI: http://dx.doi.org/10.1590/S0034-71672013000600004

7. Góes FGB, La Cava AM. Practical educative in health of the nurse with the family of the hospitalized child. Rev. eletrônica enferm. 2009 [cited 2018 Jul 15]; 11(4):942-51. DOI: https://doi.org/10.5216/ree.v11i4.33250

8. Minayo MCS. O desafio do conhecimento. 14a ed. São Paulo: HUCITEC-ABRASCO; 2014.

9. Soratto J, Pires DEP, Cabral IE, Lazzari DD, Witt RR, Sipriano CAS. A creative and sensitive way to research. Rev. bras. enferm. (Online). 2014 [cited 2018 Jul 15]; 67(6):994-9. DOI: http://dx.doi.org/10.1590/0034-7167.2014670619

10. Nascimento LCN, Souza TV, Oliveira ICS, Moraes JRMM, Aguiar RCB, Silva LF. Theoretical saturation in qualitative research: an experience report in interview with schoolchildren. Rev. bras. enferm. (Online). 2018 [cited 2018 Jul 15]; 71(1):228-33. DOI: http://dx.doi.org/10.1590/0034-7167-2016-0616

11. Ministério da Saúde (Br). Portaria no 2.068, de 21 de outubro de 2016. Intitui diretrizes para a organização da atenção integral e humanizada à mulher e ao recém-nascido no Alojamento Conjunto. Brasília (DF): Gabinete Ministerial;2016.

12. Rodrigues DP, Dodou HD, Lago PN, Mesquita NS, Melo LPT, Souza AAS. Care for both mother and child immediately after childbirth: a descriptive study. Online braz. j. nurs. (Online). 2014 [cited 2018 Jul 15]; 13(2):227-38. Available from: http://www.objnursing.uff.br/index.php/nursing/article/view/4231

13. Rocci E, Fernandes RAQ. Breastfeeding difficulties and influence in the early weaning. Rev. bras. enferm. (Online). 2014 [cited 2018 Jul 15]; 67(1):22-7. DOI: http://dx.doi.org/10.5935/0034-7167.20140002

14. Miranda JOF, Santos DV, Camargo CL, Rosa DOS, Sobrinho CLN, Mussi FC. Evidence for umbilical stump care practices: integrative review. Rev. enferm. UFPE on line. 2016 [cited 2018 Jul 15]; 10(Supl. 2):821-9. Available from: https://periodicos.ufpe.br/revistas/revistaenfermagem/article/view/11025

15. Santos SV, Costa R. Prevention of newborn skin lesions: knowledge of the nursing team. Texto contexto enferm. [Internet] 2015 [cited $2018 \mathrm{Jul}$ 15]; 24(3):731-9. DOI: http://dx.doi.org/10.1590/0104-07072015011230014

16. Alcantara KL, Brito LLMS, Costa DVS, Façanha APM, Ximenes LB, Dodt RCM. Family guidelines needed for a safe hospital of the premature newborn: integrative review. Rev. enferm. UFPE on line. 2017 [cited 2018 Jul 15]; 11(2):645-55. DOI: https://doi.org/10.5205/1981-8963-v11i2a11984p645-655-2017

17. Góes FGB, Cabral IE. Discourses on discharge care for children with special healthcare needs. Rev. bras. enferm. (Online). 2017 [cited 2018 Jul 15]; 70(1):154-61. DOI: http://dx.doi.org/10.1590/0034-7167-2016-0248

18. Dias ESM, Rodrigues ILA, Miranda HR, Corrêa JA. Conversation wheel as education strategy in health for nursing. Rev. pesqui. cuid. fundam. (Online). 2018 [cited 2018 Jul 15]; 10(2):379-84. DOI: http://dx.doi.org/10.9789/2175-5361.2018.v10i2.379-384

19. Góes FGB, Cabral IE. Hospital discharge in children with special health care needs and its different dimensions. Rev. enferm. UERJ [Internet]. 2017 [cited 2018 Jul 15]; 25:e18684. DOI: http://dx.doi.org/10.12957/reuerj.2017.18684

20. Veronez $\mathrm{M}$, HigarashilH. A protocol for hospital discharge of premature babies: input to building a proposal. Rev. enferm. UERJ [Internet] 2016 [cited 2018 Jul 15]; 24(3):e7505. DOI: https://doi.org/10.12957/reuerj.2016.7505 